\title{
Parietal scalp is another affected area in female pattern hair loss: an analysis of hair density and hair diameter
}

\author{
Salinee Rojhirunsakool \\ Poonkiat Suchonwanit \\ Department of Medicine, Division \\ of Dermatology, Faculty of Medicine, \\ Ramathibodi Hospital, Mahidol \\ University, Bangkok, Thailand
}

This article was published in the following Dove Press journal: Clinical, Cosmetic and Investigational Dermatology

Purpose: Female pattern hair loss (FPHL) is a common hair disease. However, studies of the quantitative measurement of FPHL are still limited. The aim of this study was to investigate the characteristics of hair density and hair diameter in normal women and FPHL patients, and further correlate the quantitative measurement with the clinical presentation of FPHL.

Patients and methods: An evaluation of 471 FPHL patients and 236 normal women was carried out according to the Ludwig classification, and analysis was performed by using a computerized handheld USB camera with computer-assisted software. Various areas of the scalp, including frontal, parietal, midscalp, and occipital, were analyzed for hair density, non-vellus hair diameter, and percentage of miniaturized hair.

Results: The hair density in normal women was the highest and the lowest in the midscalp and parietal areas, respectively. The FPHL group revealed the lowest hair density in the parietal area. Significant differences in hair density, non-vellus hair diameter, and percentage of miniaturized hair between the normal and FPHL groups were observed, especially in the midscalp and parietal areas.

Conclusion: The parietal area is another important affected area in FPHL in addition to the midscalp area. This finding provides novel important information of FPHL and will be useful for hair transplant surgeons choosing the optimal donor sites for hair transplantation in women.

Keywords: androgenetic alopecia, alopecia, phototrichogram, miniaturization

\section{Introduction}

Female pattern hair loss (FPHL) is the most common cause of hair loss in women worldwide. It is characterized by progressive hair thinning at the crown with preservation of the frontal hairline, which is caused by progressive transformation of terminal hair to miniaturized hair and a shortening of the anagen phase in each hair cycle. ${ }^{1}$ The affected scalp shows a prolongation and an increase in the number of the kenogen (interval between shedding of the telogen and re-entry into anagen), resulting in clinically apparent alopecia. ${ }^{2}$

Despite FPHL being a very common hair disease, diagnosis of the condition is still based on patient history and physical examination, which is sometimes not straightforward. Therefore, various methods have been developed to provide an objective measurement for hair loss, ${ }^{3,4}$ ranging from invasive methods such as scalp biopsy to noninvasive methods such as wash test, dermatoscope, and phototrichogram. ${ }^{5,6}$ In hair loss patients who are already concerned about their appearance, it is common that patients do not accept methods that tend to negatively affect their hair, such as biopsy,
Correspondence: Poonkiat Suchonwanit Division of Dermatology, Faculty of Medicine, Ramathibodi hospital, Mahido University, 270, Rama VI Road, Thung Phaya Thai, Ratchathewi, Bangkok 10400 , Thailand

Tel $+66220 \mathrm{I}$ I |4

Fax +662201 12II

Email poonkiat@hotmail.com 
plucking, or trimming hair. Hence, for these patients, noninvasive techniques for evaluation of hair loss are preferable..$^{3,4}$

Recently, the automated phototrichogram was developed. It is a novel method that combines the use of a digital videomicroscope with an image analysis system for measurement of hair. ${ }^{3}$ This noninvasive technique can be used for measurement of hair density, hair thickness, scalp abnormalities, and so on. The advantage of the system is that it can be used in a real-life clinic setting without cutting, dyeing, or plucking hairs. However, as the system was only recently developed, there is still little information regarding baseline values in normal women and FPHL patients, especially in Asian women. Therefore, we aimed to study the hair density and hair diameter of scalp hair in normal women and FPHL patients. In addition, we studied the correlation between the quantitative measurements obtained by computer-assisted software compared with the clinical presentation of FPHL.

\section{Patients and methods}

After the Mahidol University Institutional Review Board approved the study protocol (protocol number 04-56-04), we recruited subjects who visited the dermatology clinic at Ramathibodi Hospital, Mahidol University. The subjects were evaluated in a single visit and were categorized into two groups. The group of normal scalp hair women comprised women who visited the dermatology clinic with skin problems other than hair and scalp diseases. The other group was women who were diagnosed as FPHL cases according to the Ludwig classification. In uncertain cases, the definite diagnosis was confirmed by performing a scalp biopsy. Subjects were women aged $>15$ years, and all agreed to participate in the study. The exclusion criteria included 1) presence of other hair or scalp disorders; 2) history of anemia, thyroid disease, nutritional deficiency, autoimmune disease, or other systemic disease; 3) history of acute hair loss within 6 months; 4) usage of drugs that can affect hair growth; and 5) history of hair restoration surgery. All patients (or parents of any patients under the legal age of consent) provided written informed consent to participate in the study and to permit use of their photographs for publication.

Four different areas of each subject's scalp were evaluated. The midscalp area was the area on the middle of an imaginary line between the left and right external auditory ear canals (Figure 1A). The frontal area was the area at the point $1 \mathrm{~cm}$ above the middle of the frontal hairline (Figure 1B). The occipital area was the area on the middle of a horizontal line across the greater occipital protuberance (Figure 1C). Finally, the parietal area was the area at point $7 \mathrm{~cm}$ above

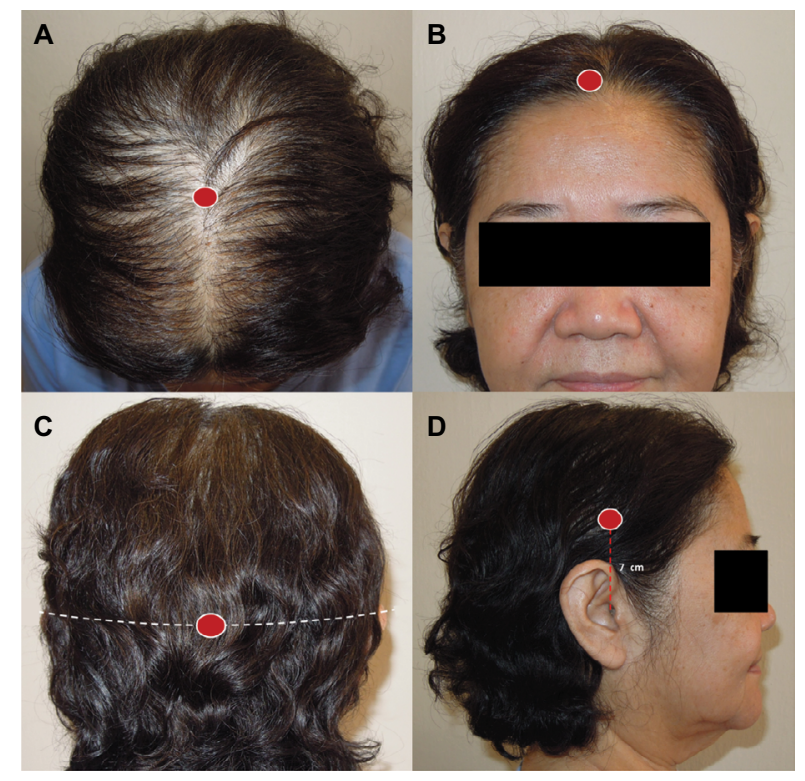

Figure I Measurement points (red dots) at midscalp (A), frontal area (B), occipital area $(\mathbf{C})$, and parietal area (D).

both external auditory ear canals (Figure 1D). The data from the parietal area was the average of values measured from both sides in each subject.

The measurement of hair density (number of hairs per $\mathrm{cm}^{2}$ ), the diameter of non-vellus hair (hair shaft diameter more than $30 \mu \mathrm{m}$ ), and the percentage of miniaturized hair (hair shaft diameter $\leq 30 \mu \mathrm{m}$ ) in this study were performed using a computerized handheld USB camera with computer-assisted software (Folliscope ${ }^{\circledR}$; LeadM Corp., Seoul, South Korea). Digital images were recorded in 50-fold magnification in the areas of $36.48 \mathrm{~cm}^{2}$. Each site was measured and photographed three times. The average values at each measurement point were then used in statistical analysis. All values obtained were rechecked by manual counting for more precise results.

For the statistical analysis, the hair density and nonvellus hair diameter were analyzed by two-sample $t$-test and expressed as mean $\pm \mathrm{SD}$. The percentage of miniaturized hair was analyzed by Wilcoxon signed-rank test and expressed as median and range. $p<0.05$ was considered to be statistically significant. SPSS software version 18.0 (SPSS Inc., Chicago, IL, USA) was used for all statistical analyses.

\section{Results}

A total of 707 women aged 16-76 years participated in our study. The normal scalp hair group comprised 236 women with a mean age of $43.2 \pm 12.6$ years. In the group of 471 FPHL subjects, 165 had FPHL stage I (Ludwig I), 172 had FPHL stage II (Ludwig II), and 134 had FPHL stage III (Ludwig III). The mean ages of the Ludwig I, Ludwig II, and 
Ludwig III groups were $40.4 \pm 11.3,42.5 \pm 12.2$, and $45.1 \pm 9.6$ years, respectively.

\section{Hair density}

The mean hair density at the different sites on the scalp is shown in Table 1. The hair density in the normal group had variation at different sites. The highest density was in the midscalp, followed by the occipital, frontal, and parietal areas, respectively. Interestingly, in the normal group, the parietal area had significantly lower hair density compared with the other sites. In the FPHL groups, all areas showed a tendency to present decreasing hair densities with increases in clinical staging. Moreover, the parietal area was still the part of the scalp showing the lowest hair density in all FPHL stages.

Figure 2 demonstrates the comparison of the mean hair densities between normal subjects and each Ludwig stage. All four areas of the scalp showed a tendency toward decreasing hair density with increasing severity of the disease. In frontal sites, the decrease in hair density was statistically significant only for Ludwig III $(p<0.001)$ compared with the normal group. In contrast, statistically significant differences in mean hair densities were detected in the midscalp and parietal areas, respectively, for Ludwig I ( $p<0.001, p=0.011)$, Ludwig II $(p<0.001, p<0.001)$, and Ludwig III $(p<0.001, p<0.001)$ compared with the normal group. The occipital area had statistically significant differences in hair densities for Ludwig II $(p<0.001)$ and Ludwig III $(p<0.001)$. When calculated as percentage of difference of hair density between the normal group and each Ludwig group, the midscalp area showed the highest percentage of decreased hair density followed by the parietal, occipital, and frontal areas.

\section{Non-vellus hair diameter}

A comparison of the mean non-vellus hair diameters between normal subjects and each Ludwig stage is shown in Table 1 . The changes in non-vellus hairs that contributed to global change of the scalp were observed. In our study, non-vellus hairs were defined as hairs that had diameters larger than $30 \mu \mathrm{m}$ in order to exclude miniaturized hairs. In the normal group, the mean diameter of non-vellus hairs was similar in all four areas of the scalp. The mean diameter of non-vellus hairs in all areas of the scalp tended to decrease with increasing severity of FPHL. When comparing between the normal group and each Ludwig stage, the frontal and the occipital areas showed a trend toward decreasing non-vellus hair diameter, but with no statistical significance. However, the midscalp and parietal areas showed progressively decreasing non-vellus hair diameters for Ludwig II $(p<0.001, p=0.005)$ and Ludwig III $(p<0.001, p<0.001)$ compared with the normal group.

\section{Percentage of miniaturized hair}

The percentage of miniaturized hair in both the normal and FPHL groups is summarized in Table 1. In the normal group, the area that had the highest percentage of miniaturized hair was the frontal area. The occipital area had the lowest percentage of miniaturized hair. However, there was no statistically significant difference observed between the various areas of the scalp in the normal group. When comparing the percentage of miniaturized hair in normal women to each FPHL group, all four areas had a tendency toward increasing percentages of miniaturized hair with higher Ludwig staging. The midscalp and parietal areas were the areas that

Table I Mean hair density (hairs $\left./ \mathrm{cm}^{2}\right)$, diameter of non-vellus hair $(\mu \mathrm{m})$, and percentage of miniaturized hair $(\%)$ in each area of the scalp

\begin{tabular}{|c|c|c|c|c|}
\hline Subject groups & Frontal & Midscalp & Parietal & Occipital \\
\hline & \multicolumn{4}{|c|}{ Hair density (hairs $\left./ \mathrm{cm}^{2}\right)^{\mathrm{a}}$} \\
\hline Normal & $152.4 \pm 2 \mid .2$ & $168.6 \pm 22.4$ & $121.3 \pm 18.4$ & $163.2 \pm 22.6$ \\
\hline Ludwig I & $150.1 \pm 19.7$ & $151.8 \pm 24.3^{*}$ & $116.7 \pm 17.3^{*}$ & $159.3 \pm 20.5$ \\
\hline Ludwig II & $148.6 \pm 20.1$ & $139.9 \pm 20.6 *$ & $101.9 \pm 15.4^{*}$ & $|49.1 \pm 2| .4^{*}$ \\
\hline \multirow[t]{2}{*}{ Ludwig III } & $143.8 \pm 23.7^{*}$ & $|27.8 \pm 2| .7^{*}$ & $95.8 \pm 16.9 *$ & $140.4 \pm 20.8^{*}$ \\
\hline & \multicolumn{4}{|c|}{ Diameter of non-vellus hair $(\mu \mathrm{m})^{\mathrm{a}}$} \\
\hline Normal & $86.7 \pm 8.8$ & $85.1 \pm 9.2$ & $84.2 \pm 7.6$ & $84.5 \pm 8.6$ \\
\hline Ludwig I & $85.8 \pm 7.5$ & $84.7 \pm 8.3$ & $83.7 \pm 8.4$ & $84.1 \pm 9.5$ \\
\hline Ludwig II & $85.3 \pm 9.5$ & $81.3 \pm 8.4^{*}$ & $81.8 \pm 9.3^{*}$ & $83.8 \pm 8.9$ \\
\hline \multirow[t]{2}{*}{ Ludwig III } & $85.1 \pm 7.9$ & $78.4 \pm 10.6^{*}$ & $79.5 \pm 10.2^{*}$ & $82.7 \pm 9.8$ \\
\hline & \multicolumn{4}{|c|}{ Percentage of miniaturized hair (\%) ${ }^{\mathrm{b}}$} \\
\hline Normal & $13(3-4 \mid)$ & II (2-25) & $10(2-31)$ & $9(2-22)$ \\
\hline Ludwig I & $16(7-63)$ & $20(8-65)^{*}$ & $14(7-3 \mid)^{*}$ & $10(1-17)$ \\
\hline Ludwig II & $24(2-45)^{*}$ & $29(5-6 I)^{*}$ & $20(6-43)^{*}$ & $14(3-26)^{*}$ \\
\hline Ludwig III & $26(7-66)^{*}$ & $31(4-67)^{*}$ & $26(7-54)^{*}$ & $15(2-35)^{*}$ \\
\hline
\end{tabular}

Notes: ${ }^{a}$ Values are presented as mean \pm standard deviation. ${ }^{b}$ Values are presented as median and range. ${ }^{*} p<0.05$ for the comparison between the normal group and each Ludwig stage in the same area of the scalp. 
had statistically significant increases for Ludwig I $(p<0.01$, $p=0.04)$, and further increased for Ludwig II $(p<0.001$, $p<0.001)$ and Ludwig III $(p<0.001, p<0.001)$. Meanwhile, in the frontal and occipital areas, significant differences were found only in Ludwig II ( $p=0.006, p=0.01)$ and Ludwig III $(p=0.01, p=0.01)$.

\section{Discussion}

Hair density and hair diameter in various ethnic groups have been studied using various methods. ${ }^{7-17}$ Most previous studies have investigated the normal population. Asians are known to have a lower number of hairs compared with other ethnicities. In previous studies in Caucasians, the hair densities of normal subjects were much higher than in the present study. ${ }^{7-11}$ However, a previous study in Korean women showed that the hair density was similar to our study. ${ }^{12}$ In terms of hair diameter, most of the previous studies reported only the midscalp area. The present values appear to be similar to those of previous studies, even though different measurement techniques were used (Table 2).

Interestingly, hairs at different scalp areas have different characteristics. Measurements of different areas of the scalp revealed that the parietal area had the lowest hair density, even in normal subjects. The overall change in FPHL subjects showed a decrease in hair density and non-vellus hair diameter, and an increase in miniaturized hair with higher Ludwig staging. The midscalp and parietal areas of FPHL subjects were the two areas that demonstrated the distinctive progression, resulting in the clinical picture of hair thinning on both areas (Figure 3). FPHL subjects had statistically significant decreases in hair density and diameter on midscalp and parietal areas. The findings are

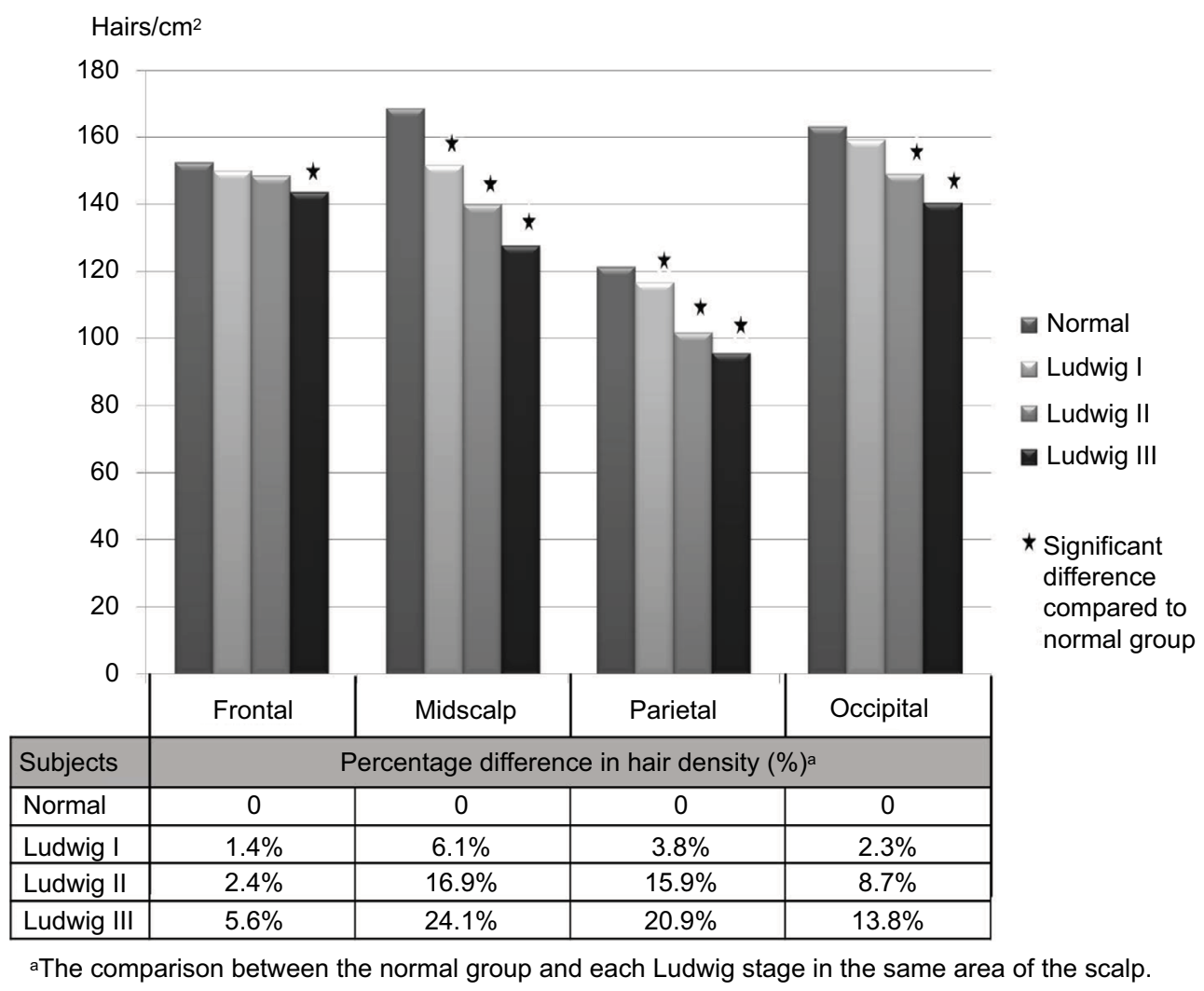

Figure 2 The hair densities and the percentage difference between normal and FPHL groups.

Abbreviation: FPHL, female pattern hair loss.

Table 2 The comparison of normal females' scalp hair with previous studies

\begin{tabular}{|c|c|c|c|c|c|c|}
\hline \multirow{2}{*}{$\begin{array}{l}\text { Race } \\
\text { Country }\end{array}$} & \multicolumn{2}{|l|}{ Asian } & \multicolumn{4}{|l|}{ Caucasian } \\
\hline & Thailand & Korea & UK & Turkey & Turkey & Italy \\
\hline Authors, year & $\begin{array}{l}\text { Rojhirunsakool and } \\
\text { Suchonwanit, present study }\end{array}$ & $\begin{array}{l}\text { Kang et al, } \\
2009^{\prime \prime}\end{array}$ & $\begin{array}{l}\text { Birch et al, } \\
200 \mathrm{I}^{7}\end{array}$ & $\begin{array}{l}\text { Ekmekci et al, } \\
2006^{9}\end{array}$ & $\begin{array}{l}\text { Aktan et al, } \\
2007^{6}\end{array}$ & $\begin{array}{l}\text { D'Amico et al, } \\
2001^{8}\end{array}$ \\
\hline $\begin{array}{l}\text { Hair density of } \\
\text { midscalp (hairs } / \mathrm{cm}^{2} \text { ) }\end{array}$ & 168 & 161 & 290 & 261 & 213 & 300 \\
\hline Hair diameter $(\mu \mathrm{m})$ & 85 & 80 & 83 & - & - & 84 \\
\hline
\end{tabular}




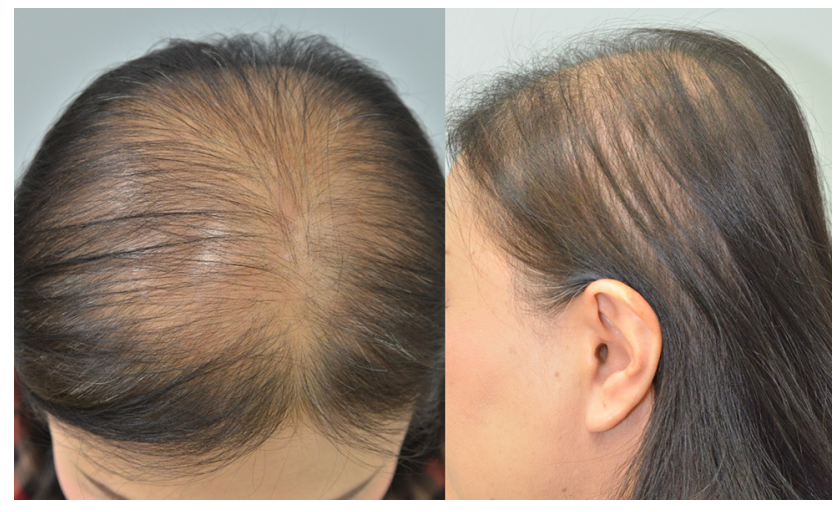

Figure 3 The clinical presentation of FPHL reveals distinctive hair thinning mostly confined to the midscalp and parietal areas.

Note: The frontal hair line is usually spared.

Abbreviation: FPHL, female pattern hair loss.

similar to a previous study by Kang et al that reported the changing patterns of hair density and diameter in women with hair loss. ${ }^{12}$ In addition, our study revealed an increasing percentage of miniaturized hairs with higher Ludwig staging. To our knowledge, the finding of significantly increased miniaturized hairs on the parietal area of patients with FPHL has never been described before. Most studies have typically focused on the midscalp or occipital areas. Therefore, it is possible that the pattern of hair loss in FPHL involves both the midscalp and parietal areas. FPHL patients are frequently observed to have hair thinning at the parietal area and the midscalp area. These findings provide novel important information on the hair characteristics of FPHL. However, the parietal area may not be the primary concern of patients. Hair thinning may not be obviously seen because the direction of hair growth can help cover the parietal area of the scalp.

The differences of hair parameters on each scalp area may be explained by the embryological derivation. The dermis of the face and anterior scalp, including the frontal and parietal areas, is of neural crest origin, while the dermis of the occipital area is of mesodermal origin. ${ }^{18}$ Because frontal and parietal scalps share their embryological background, the pathophysiology of parietal scalp involvement in FPHL could be explained by increased $5 \alpha$-reductase enzyme in this area compared to unaffected scalp, which is the same mechanism described on frontal scalp involvement. ${ }^{19}$ However, further studies are needed to elucidate the pathophysiology of FPHL on parietal scalp area.

The diagnosis of FPHL is often challenging to determine because of subjectivity of physicians' examination. In patients with suspected early FPHL, history taking and physical examination lack the conclusiveness for accurate determination of stage and severity. Therefore, with the measurement of hair density and diameter by computer-assisted software, it offers practitioners quantitative data to identify the disease. Moreover, it is a noninvasive and easy-to-use method in outpatient clinic.

The limitation in our study is possible because of clinical diagnosis of FPHL. We could not clearly exclude participants with chronic telogen effluvium. Performing the wash test and/ or scalp biopsies to confirm the diagnosis in further studies could solve this limitation.

From the present study, the measurement of hair density and diameter by computer-assisted software has proven to be a useful method to help in evaluating FPHL patients. All parameters (hair density, non-vellus hair diameter, and percentage of miniaturized hairs) were correlated well with clinical Ludwig staging. However, hair density and percentage of miniaturized hairs were more consistent and sensitive than non-vellus hair diameter. We suggest that by using hair density and percentage of miniaturized hairs, automated phototrichogram technology may aid physicians in the diagnosis of FPHL, particularly in its early stages. Moreover, the changing patterns on each scalp site found in the study provide us with important information for better understanding of FPHL and inform hair transplant surgeons in choosing the optimal donor sites for hair transplantation in women.

\section{Conclusion}

The measurement of hair density and diameter by computerassisted software can be a useful method in real-life clinical settings. Our study demonstrated that there was good correlation between the quantitative measurements and the clinical staging of FPHL. The values of all parameters established in normal Thai women and FPHL subjects in our study will serve as helpful reference data for the evaluation of hair disorders. Furthermore, from measurements at different sites of the scalp, we found that the parietal and midscalp areas were both involved in FPHL subjects. This interesting finding warrants further investigation in the future.

\section{Acknowledgments}

The authors thank the patients who participated in the study.

\section{Author contributions}

Both authors contributed toward data analysis, drafting and revising the paper and agree to be accountable for all aspects of the work.

\section{Disclosure}

The authors report no conflicts of interest in this work. 


\section{References}

1. Olsen EA. Female pattern hair loss. J Am Acad Dermatol. 2001; 45:S70-S80.

2. Messenger AG, Sinclair R. Follicular miniaturization in female pattern hair loss: clinicopathological correlations. Br J Dermatol. 2006; 155(5):926-930.

3. Ulrike Blume-Peytavi KH, Marcella Guarrera Hair Growth Assessment Techniques. In: Ulrike Blume-Peytavi AT, David A. Whiting, Ralph M. Trüeb, editors, Hair Growth and Disorders. Berlin: Springer; 2008:125-157.

4. Dhurat R, Saraogi P. Hair evaluation methods: merits and demerits. Int J Trichology. 2009;1(2):108-119.

5. Ko JH, Huang YH, Kuo TT. Hair counts from normal scalp biopsy in Taiwan. Dermatol Surg. 2012;38(9):1516-1520.

6. Karadag Kose O, Gulec AT. Clinical evaluation of alopecias using a handheld dermatoscope. J Am Acad Dermatol. 2012;67(2):206-214.

7. Aktan S, Akarsu S, Ilknur T, Demirtasoglu M, Ozkan S. Quantification of female pattern hair loss: a study in a Turkish population. Eur J Dermatol. 2007;17(4):321-324.

8. Birch MP, Messenger JF, Messenger AG. Hair density, hair diameter and the prevalence of female pattern hair loss. Br J Dermatol. 2001;144(2):297-304.

9. D’amico D, Vaccaro M, Guarneri F, Borgia F, Cannavo S, Guarneri B. Phototrichogram using videomicroscopy: a useful technique in the evaluation of scalp hair. Eur J Dermatol. 2001;11:17-20.

10. Ekmekci TR, Koslu A. Phototrichogram findings in women with androgenetic alopecia. Skin Res Technol. 2006;12(4):309-312.
11. Lee BS, Chan JY, Monselise A, Mcelwee K, Shapiro J. Assessment of hair density and caliber in Caucasian and Asian female subjects with female pattern hair loss by using the Folliscope. J Am Acad Dermatol. 2012;66(1):166-167.

12. Kang H, Kang TW, Lee SD, Park YM, Kim HO, Kim SY. The changing patterns of hair density and thickness in South Korean women with hair loss: clinical office-based phototrichogram analysis. Int J Dermatol. 2009;48:14-21.

13. Tajima M, Hamada C, Arai T, Miyazawa M, Shibata R, Ishino A. Characteristic features of Japanese women's hair with aging and with progressing hair loss. J Dermatol Sci. 2007;45(2):93-103.

14. Lopez V, Martin JM, Sanchez R, Ortega C, Ricart JM. Usefulness of TrichoScan professional in the evaluation of hair loss in females. Report of 180 cases. J Eur Acad Dermatol Venereol. 2011;25(9): 1068-1072.

15. Riedel-Baima B, Riedel A. Use of the TrichoScan to assess female pattern hair loss. Dermatol Surg. 2009;35(4):651-655.

16. Saraogi PP, Dhurat RS. Automated digital image analysis (TrichoScan $®$ ) for human hair growth analysis: ease versus errors. Int J Trichology. 2010;2:5-13.

17. Van Neste DJ, De Brouwer B, De Coster W. The phototrichogram: analysis of some technical factors of variation. Skin Pharmacol. 1994;7(1-2):67-72.

18. Price VH. Androgenetic alopecia in women. J Investig Dermatol Symp Proc. 2003;8:24-27.

19. Sawaya ME, Price VH. Different levels of 5alpha-reductase type I and II, aromatase, and androgen receptor in hair follicles of women and men with androgenetic alopecia. J Invest Dermatol. 1997;109(3):296-300.
Clinical, Cosmetic and Investigational Dermatology

\section{Publish your work in this journal}

Clinical, Cosmetic and Investigational Dermatology is an international, peer-reviewed, open access, online journal that focuses on the latest clinical and experimental research in all aspects of skin disease and cosmetic interventions. This journal is included on PubMed. The manuscript management system is completely online

\section{Dovepress}

and includes a very quick and fair peer-review system, which is all easy to use. Visit http://www.dovepress.com/testimonials.php to read real quotes from published authors 